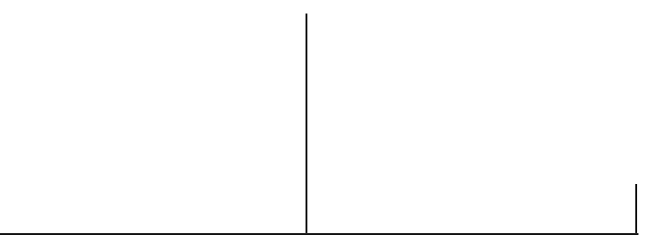

Rev. Latinoam. Psicopat. Fund., São Paulo, v. 12, n. 2, p. 285-302, junho 2009

\title{
De H. Cleckley ao DSM-IV-TR: a evolução do conceito de psicopatia rumo à medicalização da delinquência*
}

Rogério Paes Henriques

\begin{abstract}
A psicopatia é descrita como personalidade antissocial pelos manuais nosográficos contemporâneos: CID-10 e DSM-IV-TR. Contrastando tais nosografias entre si quanto aos critérios diagnósticos propostos para a psicopatia, assinalam-se as consequências de sua operacionalização, promovida, sobretudo, pelo DSM. Dentre elas, destacam-se: (1) a degradação do diagnóstico ao mero levantamento protocolar; (2) a acentuação da correlação histórica entre psicopatia e delinquência.
\end{abstract}

Palavras-chave: Psicopatia, personalidade antissocial, CID-10, DSM-IV-TR.

* Artigo inspirado em minha dissertação de mestrado: A remedicalização da psiquiatria: uma reflexão crítica sobre a revolução nosológica do DSM-III (Rio de Janeiro, IMS/UERJ, 2003). Trabalho subvencionado pela Fundação de Amparo à Pesquisa do Estado do Rio de Janeiro - Faperj. 
Tenho o direito de gozar de teu corpo

(...) e exercerei esse direito, sem que nenhum limite me detenha no capricho das extorsões que me dê gosto de nele

saciar.

(Marquês de Sade, A filosofia na alcova.)

\section{Da psiquiatria germânica do século XIX à psiquiatria anglo- -saxônica do século XX: o estreitamento do conceito de psicopatia rumo à personalidade antissocial}

Dentre os conceitos tidos como precursores da psicopatia moderna, destacam-se a manie sans delire ("loucura sem delírio" ou "loucura racional") de Pinel e a moral insanity ("loucura moral") de Prichard. Todavia, tratando-se da descrição pineliana da manie sans delire, na qual “(...) as funções do entendimento permaneciam intactas e só subsistiam à alteração da afetividade e à excitação, amiúde furiosa" (apud Bercherie, 1989 , p. 36), percebe-se que essa categoria pouco tem em comum com a atual personalidade antissocial.

Identifica-se em Morel e Lombroso descrições clínicas muito semelhantes à psicopatia moderna. Vejamos a descrição fornecida por Morel, em 1860, dos "maníacos instintivos", que apresentavam, desde a mais tenra idade, os sinais da depravação das tendências morais:

Suas tendências inatas para o mal fizeram-me designá-los do ponto de vista médico legal, pelo nome de maníacos instintivos. O incêndio, o roubo, a vagabundagem e as propensões precoces para toda sorte de desregramentos formam o triste balanço de sua existência moral, e esses infelizes (...) povoam em grandes proporções as instituições penitenciárias para a primeira infância e os presídios (apud Bercherie, 1989, p. 116). 
Por sua vez, Lombroso, no final dos anos 1880, propôs sua teoria do "delinquente nato", sugerindo uma correlação entre personalidade e tendência inata ao crime. $\mathrm{O}$ criminoso nato seria alguém marcado por certos estigmas na estrutura facial e na simetria corporal. Esta tradição, inaugurada por Lombroso, que confunde equivocadamente psicopatia e conduta criminosa, até hoje dificulta a pesquisa da psicopatia.

\section{O surgimento e a evolução do conceito de psicopatia}

$\mathrm{Na}$ literatura psiquiátrica, atribui-se frequentemente a Koch o emprego do termo "psicopático" pela primeira vez em sua obra As inferioridades psicopáticas, de 1891. Segundo Werlinder (apud Caldeira, 1979, p. 22), tratar-se-ia de um anacronismo, uma vez que o termo psicopático já havia sido empregado por von Feuchetersleben (1845), Griesinger (1868) e Krafft-Ebing (1886), antes do trabalho de Koch. Contudo, esse termo, tal como empregado por tais autores, possuía uma extensão que tornava seu emprego singularmente afastado do uso corrente que dele se faz na atualidade. Portanto, deve-se à escola de psiquiatria alemã, por meio de Koch, a introdução do termo "psicopatia" na sua acepção moderna.

Vale ressaltar que, no século XIX, a expressão "psicopata" (do grego: psyché = alma; pathos $=$ paixão, sofrimento) era utilizada pela literatura médica em seu sentido amplo, para designar os doentes mentais de modo geral, não havendo ainda uma ligação entre a psicopatia e a personalidade antissocial. Freud usou essa expressão em sua acepção ampla, como o atesta seu artigo Personagens psicopáticos no palco, de 1905 ou $1906 .{ }^{1}$ Esse uso do termo "psicopatia" como sinônimo de doença mental ainda não desapareceu por completo, sobretudo na literatura não especializada. ${ }^{2} \mathrm{Na}$ Alemanha oitocentista, contudo, essa expressão foi paulatinamente adquirindo um sentido mais restrito, na medida em que ela foi sendo acoplada pela psiquiatria germânica aos conceitos de "personalidade" e "constituição".

Com os trabalhos de Kraepelin, Birnbaum e Gruhle, uma rígida fronteira entre psicopatia e psicose foi estabelecida. Segundo tais autores (apud Caldeira, 1979, p. 24-27), a psicopatia seria sempre devida a uma disposição constitucional, que poderia se manifestar ou não no decorrer da vida do indivíduo, dependendo in-

1. A data deste artigo é incerta. Pelo fato de o mesmo só ter sido publicado pos-mortem, em 1942, especula-se que ele tenha sido redigido por Freud no final de 1905 ou início de 1906.

2. Vale ressaltar que esse sentido do termo é conservado pelos dicionários da língua portuguesa.

Rev. Latinoam. Psicopat. Fund., São Paulo, v. 12, n. 2, p. 285-302, junho 2009 


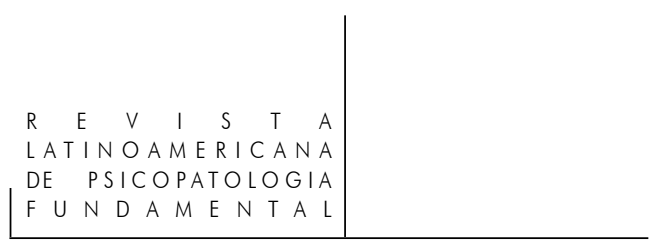

clusive de influências ambientais. No entanto, a psicopatia nunca progrediria per se para uma psicose, a qual seria sempre um fenômeno de outra ordem na vida da pessoa. Poderia haver comorbidade numa mesma pessoa das duas condições, embora nenhuma ligação etiológica pudesse haver entre elas. As tipologias negativas de Kraepelin acerca das "personalidades psicopáticas" (termo cunhado por ele na sétima edição de seu Tratado de Psiquiatria, que data de 1904) contribuiriam para o direcionamento do conceito de psicopatia rumo ao antissocial.

Numa direção totalmente oposta a de seus contemporâneos, Kretschmer, em sua obra Biótipo e caráter, de 1922, derrubaria as fronteiras entre psicopatia, psicose e normalidade, instituindo um continuum de manifestações que iam da normalidade à doença. Sua controversa ideia de que a personalidade psicopática era uma forma atenuada de transtorno mental (como, por exemplo, transtorno esquizoide e paranoide da personalidade) não seria plenamente aceita.

Kurt Schneider (1968) adotaria a nosografia kraepeliniana relativa às personalidades psicopáticas, renegando, contudo, as denominações de tipos com base em características socialmente negativas. À semelhança de Gruhle, Schneider concebia a psicopatia como uma variação a partir da média, que tanto poderia ter um caráter negativo (antissocial) quanto um positivo (gênio). Apesar de também enfatizar o valor da disposição constitucional em detrimento das experiências e vivências pessoais na patogenia da psicopatia, ele a concebia como sendo o fruto de desvios quantitativos, e não como uma manifestação mórbida em si mesma. Para Schneider, as personalidades psicopáticas seriam subtipos de personalidades anormais (variações estatísticas da média normal), com a peculiaridade de sofrerem ou fazerem sofrer a sociedade com sua anormalidade.

\section{O estreitamento do conceito de psicopatia em torno da personalidade antissocial}

Com a crescente influência da psicanálise e da fenomenologia no campo psiquiátrico ocidental a partir da segunda metade do século XX, durante o pós-guerra, os conceitos germânicos sobre psicopatia tiveram um declínio de importância, em vista da maior ênfase concedida aos fatores externos na formação da subjetividade.

"O conceito de 'neurose', muito mais popular tanto nos círculos psiquiátricos quanto junto aos leigos, por ser identificado com a psicogênese, e, consequentemente, com uma maior esperança na ação das psicoterapias, engoliu a psicopatia germânica" (Caldeira, 1979, p. 38). Paralelamente, o conceito de psicopatia foi se restringindo e se associando ao antissocial, que passou a predominar a partir de então. A delimitação clínica da psicopatia enquanto personalidade antissocial seria efetivamente estabelecida pelos teóricos da 
psiquiatria anglo-saxônica moderna, sobretudo pelo norte-americano Hervey Milton Cleckley (1903-1984).

The Mask of Sanity (A máscara da sanidade), primeira edição de 1941, é o livro de Cleckley (1988) sobre a psicopatia. Logo no título, percebe-se uma alusão à ideia central do autor, qual seja: que a psicopatia é uma forma de doença mental, porém, sem os típicos sintomas das psicoses, o que conferiria ao psicopata uma aparência de normalidade. Para Cleckley, o transtorno fundamental da psicopatia seria a "demência semântica", isto é, um déficit na compreensão dos sentimentos humanos em profundidade, embora no nível comportamental o indivíduo aparentasse compreendê-los. Em sua obra, o autor enfatiza, com frequência, o papel da constituição na etiologia da psicopatia. Tendo desenvolvido predominantemente um trabalho clínico-descritivo, Cleckley baseou-se nas histórias de 15 pacientes, ${ }^{3}$ sem se debruçar sobre teorias psicopatológicas. Esse autor agrupa as principais características do psicopata em dezesseis itens:

1. Aparência sedutora e boa inteligência

2. Ausência de delírios e de outras alterações patológicas do pensamento

3. Ausência de "nervosidade" ou manifestações psiconeuróticas

4. Não confiabilidade

5. Desprezo para com a verdade e insinceridade

6. Falta de remorso ou culpa

7. Conduta antissocial não motivada pelas contingências

8. Julgamento pobre e falha em aprender através da experiência

9. Egocentrismo patológico e incapacidade para amar

10. Pobreza geral na maioria das reações afetivas

11. Perda específica de insight (compreensão interna)

12. Não reatividade afetiva nas relações interpessoais em geral

13. Comportamento extravagante e inconveniente, algumas vezes sob a ação de bebidas, outras não

14. Suicídio raramente praticado

15. Vida sexual impessoal, trivial e mal integrada

16. Falha em seguir qualquer plano de vida (Cleckley, 1988, p. 337-338). ${ }^{4}$

3. Na primeira parte da seção 2 de seu livro, Cleckley (1988, p. 29-187) fornece-nos farto material clínico com base nos casos de Max, Roberta, Arnold, Tom, George, Pierre, Frank, Anna, Jack, Chester, Walter, Joe, Milt, Gregory e Stanley.

4. (1) Superficial charm and good "intelligence"; (2) Absence of delusions and other signs of irrational thinking; (3) Absence of "nervousness" or psychoneurotic manifestations; (4) Unreliability; (5) Untruthfulness and insincerity; (6) Lack of remorse or shame; (7) Inadequately 


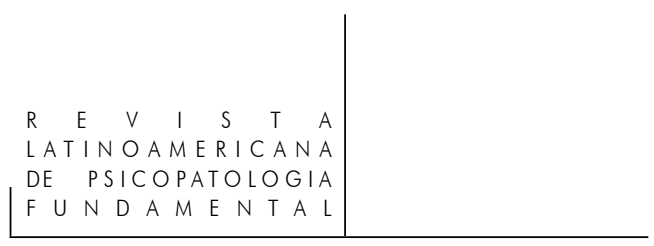

A tipologia de Cleckley (1988) do psicopata encontra-se descrita na terceira parte da seção 3 de seu livro (p. 337-364) e será resumida a seguir. Interessante que Cleckley intercala suas descrições tipológicas com fragmentos ilustrativos de casos clínicos, imprimindo um dinamismo ao texto.

O psicopata causaria uma boa impressão às pessoas à primeira vista, raramente sendo visto como um indivíduo dissimulado. Com frequência, ele age com bom senso e demonstra um raciocínio lógico eficiente, sendo capaz de prever as consequências de seus atos antissociais, elaborar projetos de vida admiráveis e criticar-se quanto aos seus erros do passado. Seus argumentos são firmes e bem-estruturados. Ele parece ser uma pessoa descolada, no sentido de ser livre de empecilhos sociais ou emocionais. Parece responder com sentimentos adequados às situações sociais nas quais lhe são exigidas respostas afetivas. Não apresenta sintomas de psicoses e, normalmente, também não há sintomas sugestivos de uma neurose. De fato, as manifestações neuróticas clássicas praticamente lhes são ausentes, assim como parece ser imune à angústia ou preocupação diante de situações perturbadoras.

Apesar da boa impressão inicial causada pelo psicopata, logo se descobrirá, a partir de situações cotidianas, que ele não possui senso de responsabilidade, independentemente do tipo de compromisso assumido, seja ele trivial ou sério. A confrontação com suas falhas ou com sua deslealdade parece não influenciar nas suas atitudes. Contudo, o psicopata não age de modo antissocial todo o tempo, sendo comum a alternância com condutas socialmente aceitas e valorizadas - ele pode, por um determinado período, frequentar o trabalho regularmente, pagar suas contas em dia ou ignorar oportunidades para cometer atos ilícitos. Não se pode prever quanto tempo vai durar sua boa conduta, dado que uma recidiva é quase certa.

O psicopata mostra total desconsideração pela verdade e não compreende a atitude das pessoas que a valorizam e a cultivam. Tipicamente, ele não se sente constrangido ao mentir, fazendo-o, muitas vezes, de modo mais convincente que uma pessoa que diz a verdade. Quando desmascarado, ele não sente qualquer remorso e só se defende para se desvencilhar de um problema real ou para atingir algum objetivo, nunca para reparar sua reputação.

motivated antisocial behavior; (8) Poor judgment and failure to learn by experience; (9) Pathologic egocentricity and incapacity for love; (10) General poverty in major affective reactions; (11) Specific loss of insight; (12) Unresponsiveness in general interpersonal relations; (13) Fantastic and uninviting behavior with drink and sometimes without; (14) Suicide rarely carried out; (15) Sex life impersonal, trivial, and poorly integrated; (16) Failure to follow any life plan.

Rev. Latinoam. Psicopat. Fund., São Paulo, v. 12, n. 2, p. 285-302, junho 2009 
O psicopata não se sente culpado pelos vários importunos causados a si mesmo e a outrem, em função de suas ações irresponsáveis. Geralmente, ele se exime de qualquer responsabilidade por tais importunos e acusa diretamente outras pessoas. Outras vezes, numa espécie de encenação, ele diz que seus problemas são devidos aos seus erros, porém, quando questionado sobre quais problemas e quais erros estariam em questão, a incoerência de suas respostas demonstra que sua noção de culpa é apenas aparente. É difícil compreender a natureza subjacente aos atos antissociais, dada a aparente falta de lógica dos mesmos - o psicopata comete toda espécie de atos desonestos, colocando-se constantemente em situações de alto risco; Cleckley cita como exemplo, com base em seus relatos de casos, os roubos praticados pelos psicopatas cuja motivação não se atrela às contingências sociais. Apesar da inteligência acima da média, o psicopata não consegue aprender com seus erros. Nenhuma punição é passível de fazer com que o psicopata mude suas maneiras, embora as práticas punitivas, de ordem médica e jurídica, sejam as que mais recaiam sobre ele.

Outra marca característica do psicopata é seu egocentrismo. Embora sua incapacidade para o amor objetal não seja absoluta, suas reações afetivas ocorrem sempre em intensidade limitada. Isto pode ser confirmado pela sua indiferença ao sofrimento que ele mesmo provoca nas pessoas, às quais ele diz amar.

O psicopata possui uma profunda deficiência de insight (compreensão interna), que lhe acarreta um comprometimento grave em seu senso de avaliação da realidade. Ele é incapaz de estabelecer uma relação de empatia com outra pessoa. Esta deficiência é de difícil compreensão, já que ele utiliza todas as palavras, como se as compreendesse, mas, ao mesmo tempo, é alheio aos seus significados mais profundos. O psicopata não responde de forma convencional às manifestações de afeto e carinho.

O abuso de álcool é muito comum entre os psicopatas, embora se encontrem casos que fujam a essa regra. O surgimento de comportamentos extravagantes, chocantes e incompreensíveis é um ponto característico do abuso de álcool por psicopatas, sendo também um bom critério para se distinguir a psicopatia das outras condições clínicas que também abusam da bebida. Raramente o psicopata comete suicídio, sendo que as suas ameaças e tentativas nesse sentido possuem, muitas vezes, um caráter histriônico.

A vida sexual dos psicopatas é caracterizada por práticas sexuais desviantes (inclusive incestuosas), sem que isso forme um padrão de comportamento. $\mathrm{O}$ homossexualismo raramente é encontrado, ao menos enquanto a única forma de orientação sexual. De modo geral, as relações sexuais, que podem ser de vários tipos, são impessoais e não implicam relacionamentos afetivos duradouros. 


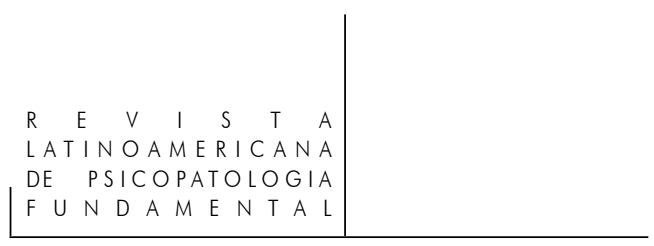

A inabilidade em seguir qualquer plano de vida de modo consistente é outra característica do psicopata, que seria confirmada pela quantidade de atividades banais que ele desenvolve ao longo de sua existência.

Cleckley considera-se original em sua abordagem da psicopatia, ressaltando o ineditismo de seus relatos de casos clínicos, quando comparados aos de seus predecessores e contemporâneos. Em parte, ele tem razão; o fato é que sua descrição da psicopatia como personalidade antissocial vigora até nossos dias, como o atestam as nosografias psiquiátricas contemporâneas: 10. ed. da Classificação Internacional de Doenças - CID-10 (OMS, 1993) e 4. edição revisada do Manual Diagnóstico e Estatístico dos Transtornos Mentais - DSM-IV-TR (APA, 2002).

\section{Psicopatia e perversão}

Antes de demonstrar como esta descrição de Cleckley constitui a base das nosografias psiquiátricas atuais, um dos problemas a serem abordados diz respeito às correlações entre psicopatia (síndrome clínica) e perversão (estrutura psíquica) e as diferenças entre o diagnóstico psiquiátrico (sindrômico) e psicanalítico (estrutural).

Shine (2000) assinala que "o termo psicopatia - e suas variantes - foi tomado de empréstimo do campo da psiquiatria por vários psicanalistas, reproduzindo, no meio psicanalítico, a mesma difusão de sentidos quanto ao que se queria dizer com tal termo" (p. 57). Portanto, não há no meio analítico nenhuma peculiaridade semântica referente ao uso dessa categoria psiquiátrica.

Atualmente, "psicopatia" (ou "sociopatia") é sinônimo de "personalidade antissocial", que denota uma disposição permanente do caráter no sentido da agressividade, da crueldade e da malignidade, determinando inexoravelmente o mal de outrem - trata-se do que outrora se designava por "perversidade", caracterizando a perversão social. Já as perversões sexuais são chamadas de "parafilias", 5 designando um padrão de comportamentos sexuais desviantes para com a moral

5. De acordo com seu ideal de neutralidade e a consequente adoção de um linguajar supostamente descritivo, a partir de sua $3^{\text {a }}$ edição de 1980, o DSM passou a denominar os antigos desvios ou perversões sexuais de "parafilias". Todavia, a nova expressão adotada pelo DSM-III apresenta a mesma acepção moralista que ele pretendeu eliminar, já que, como assinala Ferraz (2000, p. 20), parafilia significa "gosto pelo acessório", isto é, gosto pelo que não é o principal no ato sexual, o que vem a ser, na prática, gosto por práticas sexuais não genitais ou desviantes/perversas.

Rev. Latinoam. Psicopat. Fund., São Paulo, v. 12, n. 2, p. 285-302, junho 2009 
de uma dada cultura, dentre os quais se destacam, nas sociedades industriais modernas: voyeurismo, exibicionismo, fetichismo, sadismo sexual, masoquismo sexual, frotteurismo, pedofilia, zoofilia etc.

Nas nosografias psiquiátricas atuais, CID-10 e DSM-IV-TR, a psicopatia agrupa-se entre os transtornos da personalidade, sendo denominada "transtorno da personalidade antissocial". Enquanto isso, as parafilias agrupam-se entre os transtornos da esfera sexual. Tratando-se da classificação multiaxial proposta pelo DSM, a psicopatia (eixo II) e as parafilias (eixo I) aparecem em lócus diferentes, o que sugere uma diferença qualitativa, de natureza, entre elas. ${ }^{6}$ Supõe-se, nesse caso, que a psicopatia e as parafilias sejam entidades nosológicas autônomas e qualitativamente distintas entre si.

A nosografia psicanalítica, por sua vez, dilui as fronteiras entre psicopatia e parafilias, concebendo a "perversão" como uma estruturação subjetiva, isto é, como uma das saídas possíveis do complexo de Édipo, uma tomada de posição frente à ameaça de castração. ${ }^{7}$ Em seu clássico texto sobre o assunto, de 1927, Freud propôs para as perversões uma psicopatologia quase unificadora, baseada no modelo do fetichismo: "o problema resume-se sempre em renegar a ausência de pênis na mãe, para poder manter recalcada a angústia de castração, e o fetiche substitui o pênis do qual é preciso que a mãe não tenha sido privada" (apud Lanteri-Laura, 1994, p. 127; grifo meu) $;{ }^{8}$ o mecanismo psicológico da "recusa", "renegação", ou "desmentido" (Verleugnung) estaria para a perversão, assim como

6. Baseado no método clínico-descritivo/evolutivo de Kraepelin, o DSM-IV-TR divide os transtornos mentais entre os eixos I (no qual se agrupa a ampla maioria dos transtornos descritos nesse manual), referente às síndromes clínicas, isto é, aos quadros agudos com prognóstico de bom a moderado, e II, relativo aos quadros crônicos decorrentes de um desenvolvimento anômalo da personalidade ou da inteligência, geralmente com mau prognóstico. Esse prognóstico é formulado tão somente em função da resposta positiva ou negativa desses transtornos frente os neuro e psicofármacos.

7. Todavia, a perversão, enquanto estrutura psíquica particular, não necessariamente associa-se à perversidade manifesta (psicopatia). “(...) perversidade não é o mesmo que perversão, muito embora, nos casos mais graves de perversão (...) podem-se detectar evidências da perversidade tanto na transferência como nas demais relações objetais" (Ferraz, 2000, p. 21).

8. Ou, em termos lacanianos, "o fetiche é o substituto do falo imaginário, pois é essencial à função simbólica da mãe fálica na medida em que, mantendo-a neste estatuto, ele pode desmentir, subverter a lei que significa que ela está castrada simbolicamente. Ele poupa, assim, a angústia de sua própria castração" (Valas, 1990, p. 98).

9. A recusa não é um mecanismo exclusivo da perversão e possui um efeito estrutural no desenvolvimento psíquico "normal", indispensável à simbolização. Todavia, sua persistência para além da infância implica sua cristalização patológica como mecanismo de defesa predominan- 


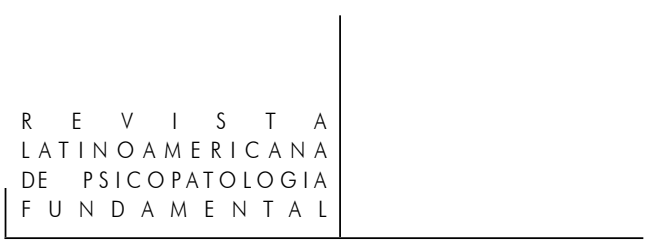

a "rejeição" ou "foraclusão" (Verwerfung) estaria para a psicose e o "recalque" ou "recalcamento" (Verdrängung) para a neurose. Nesse sentido, a nosografia psicanalítica pressupõe uma unidade psicopatológica fundamental entre a psicopatia e as parafilias em torno da "estrutura perversa", sendo a diferença entre ambas quantitativa. Para a psicanálise, importa menos as diferentes manifestações fenomenológicas dos vários tipos de "perversões" (incluindo aqui a psicopatia e as parafilias) que o mecanismo psicológico subjacente que as unifica: a Verleugnung.

O diagnóstico psicanalítico, estrutural, de perversão implica a escuta clínica da Verleugnung, a partir dos seus efeitos discursivos na fala do analisando. Queiroz (2004) sustenta haver um efeito da Verleugnung no "discurso perverso", assim como, por analogia, supomos um efeito da Verwerfung no "discurso psicótico", cuja manifestação clínica evidenciar-se-ia nas alterações de linguagem típicas da psicose: neologismos, vazios de significação, frases interrompidas etc. Segundo essa autora, no chamado "discurso perverso", a palavra se apresenta limitada na sua função de representar, levando o analisando a produzir um discurso descritivo, imagético e denotativo, sendo a hipérbole a principal figura de linguagem em seu esforço de colocar o gozo em palavras, cujo exemplo emblemático seriam os escritos do Marquês de Sade (Queiroz, 2004, p. 31). Já o diagnóstico psiquiátrico, calcado na idealizada objetividade científica, volta-se mais para o olhar perscrutador na busca por traços categoriais distintivos que sirvam de evidência para a identificação das síndromes (psicopatia e parafilias).

Essa querela entre uma nosografia psiquiátrica de inspiração positivista e a nosografia psicanalítica reflete, de fato, dois modelos antagônicos de classificação dos transtornos mentais. O modelo nosológico categorial em psiquiatria, adotado pelo DSM-IV-TR e pela CID-10, concebe os transtornos mentais como entidades mórbidas específicas. Procura-se por desvios qualitativos que justifiquem a existência de tais entidades mórbidas ou categorias. O modelo médico tradicional, baseado nas doenças infecciosas, é categorial: sabe-se que a malária é qualitativamente distinta da febre tifóide, a qual, por sua vez, distingue-se da escarlatina; da mesma forma, o câncer distingue-se qualitativamente da tuberculose, e assim por diante. As bases conceituais do modelo categorial se encontram na filosofia aristotélica. Pressupõe-se que os fenômenos observáveis (os sinais e sintomas, isto é, as síndromes) são separáveis em classes distintas e bem definidas, sendo tais classes manifestações de essências (categorias chamadas doen-

te e é nesse sentido, de uma patologia da recusa, que a abordamos aqui. Remeto o leitor ao elucidativo trabalho de Ferraz (2000).

Rev. Latinoam. Psicopat. Fund., São Paulo, v. 12, n. 2, p. 285-302, junho 2009 
ças). O que distingue uma categoria da outra são as alterações qualitativas subjacentes, identificadas, a posteriori, como bactérias, mecanismos anátomo ou fisiopatológicos, dentre outros fatores.

Já no modelo dimensional, adotado pela psiquiatria dinâmica de orientação psicanalítica, as alterações entre as patologias seriam quantitativas e a distribuição delas dar-se-ia ao longo de um continuum que variaria do patológico ao normal. No caso Schreber, por exemplo, Freud (1911, p. 84) faz alusão à possibilidade de um deslizamento recíproco entre a paranoia e a esquizofrenia, sugerindo um quadro clínico sui generis ao presidente Schreber que pouco se assemelha à nosografia psiquiátrica científica de inspiração kraepeliniana vigente na época.

Adotou-se o modelo categorial em psiquiatria a partir do seu alinhamento com o paradigma da Medicina Baseada em Evidências, empreendido pelos idealizadores do DSM-III e reforçado nas edições seguintes do DSM e na CID-10. ${ }^{10}$

Leite (2001), assinala que o DSM-III adota novos critérios estatísticos para a diagnose, criticando a metodologia de seus antecessores, e

(...) desconsidera a existência de um Sujeito na causação dos transtornos mentais (...) Nascido da psiquiatria universitária norte-americana, conhecida como escola de St. Louis, o DSM-III teria por modelo a resposta padrão à administração de uma substância química específica. Este procedimento denominado critério operacional pretendia preencher a ausência de signos patognomônicos e de exames de laboratório em psiquiatria, e, ao medicalizá-la, a retiraria de uma influência filosófica a que estaria submetida (...) (p. 137)

Por conseguinte, a "pasteurização" dos manuais nosográficos em psiquiatria, que se supõe serem "descritivos e ateóricos", implicou seu afastamento radical da psicanálise. Para a psiquiatria (re)medicalizada contemporânea (dita "biológica"), esse saber é tão indigno de figurar numa nosografia científica quanto a metafísica clássica o é para a filosofia kantiana.

Supomos que a operacionalização dos critérios diagnósticos da psicopatia, em sua nova orientação criminal-comportamental (sobretudo como proposta pelo DSM), implicou sua banalização, no sentido de sua expansão rumo ao normal, acentuando uma correlação histórica desta categoria nosológica com a marginalidade e a delinquência, e promovendo a patologização/medicalização dessas práticas desviantes.

10. No que tange aos transtornos mentais, a CID-10 adota uma perspectiva metodológica semelhante ao DSMIV. Na ocasião da elaboração desses manuais, houve uma série de consultorias entre a Associação Psiquiátrica Americana (APA) e a Organização Mundial de Saúde (OMS), que resultaria numa formulação de códigos e termos em comum acordo (Roudinesco, 2000).

Rev. Latinoam. Psicopat. Fund., São Paulo, v. 12, n. 2, p. 285-302, junho 2009 


\section{A psicopatia nas nosografias psiquiátricas contemporâneas}

Embora a descrição da psicopatia na CID-10 e no DSM-IV-TR baseie-se em Cleckley, a comparação entre ambos evidencia diferenças significativas quanto à forma como cada manual descreve essa categoria.

Na Classificação de Transtornos Mentais e de Comportamento da CID-10, os critérios diagnósticos para psicopatia são:

\section{F60.2 Transtorno de personalidade antissocial}

Transtorno de personalidade, usualmente vindo de atenção por uma disparidade flagrante entre o comportamento e as normas sociais predominantes, e caracterizado por:

(a) indiferença insensível pelos sentimentos alheios;

(b) atitude flagrante e persistente de irresponsabilidade e desrespeito por normas, regras e obrigações sociais;

(c) incapacidade de manter relacionamentos, embora não haja dificuldade em estabelecê-los;

(d) muito baixa tolerância à frustração e um baixo limiar para descarga de agressão, incluindo violência;

(e) incapacidade de experimentar culpa ou de aprender com a experiência, particularmente punição;

(f) propensão marcante para culpar os outros ou para oferecer racionalizações plausíveis para o comportamento que levou o paciente a conflito com a sociedade.

Pode também haver irritabilidade persistente como um aspecto associado. Transtorno de conduta durante a infância e a adolescência, ainda que não invariavelmente presente, pode dar maior suporte ao diagnóstico (OMS, 1993, p. 199200).

Já os critérios diagnósticos da psicopatia no DSM-IV-TR são:

Critérios Diagnósticos para 301.7 Transtorno da Personalidade Antissocial

A. Um padrão global de desrespeito e violação dos direitos alheios, que ocorre desde os 15 anos, indicado por, no mínimo, três dos seguintes critérios:

(1) incapacidade de adequar-se às normas sociais com relação a comportamentos lícitos, indicada pela execução repetida de atos que constituem motivo de detenção

Rev. Latinoam. Psicopat. Fund., São Paulo, v. 12, n. 2, p. 285-302, junho 2009 


\section{ARTIGOS}

(2) propensão para enganar, indicada por mentir repetidamente, usar nomes falsos ou ludibriar os outros para obter vantagens pessoais ou prazer

(3) impulsividade ou fracasso em fazer planos para o futuro

(4) irritabilidade e agressividade, indicadas por repetidas lutas corporais ou agressões físicas

(5) desrespeito irresponsável pela segurança própria ou alheia

(6) irresponsabilidade consistente, indicada por um repetido fracasso em manter um comportamento laboral consistente ou de honrar obrigações financeiras

(7) ausência de remorso, indicada por indiferença ou racionalização por ter ferido, maltratado ou roubado alguém

B. O indivíduo tem no mínimo 18 anos de idade.

C. Existem evidências de Transtorno da Conduta [caracterizado por "agressão a pessoas e animais", "destruição de patrimônio", "defraudação ou furto" e "sérias violações de regras"] com início antes dos 15 anos de idade.

D. A ocorrência do comportamento antissocial não se dá exclusivamente durante o curso de Esquizofrenia ou Episódio Maníaco (APA, 2002, p. 660).

Ambos os manuais apresentam tipologias negativas para a psicopatia. Contudo, enquanto o DSM procedeu à radical operacionalização dos critérios diagnósticos propostos para a psicopatia, baseando-se tão somente em características comportamentais, reduzidas às condutas antissociais, objetiváveis e evidenciáveis, a CID-10 incluiu características psicológicas (traços de personalidade: "indiferença insensível aos sentimentos alheios"; aspectos relacionais do indivíduo: "propensão marcante para culpar os outros"; características afetivo-emocionais: "baixa tolerância à frustração", "baixo limiar para descarga de agressão") como critérios válidos para a diagnose, cujos aspectos subjetivos não podem prescindir da escuta clínica do sujeito.

Comparando-se as duas nosografias, percebe-se que, com os critérios comportamentais do DSM-IV-TR propostos para a psicopatia, o diagnóstico degrada-se ao nível do levantamento protocolar e convém cercar-se do testemunho de terceiros para esclarecer que o provável psicopata foi uma criança mentirosa e turbulenta, cruel para com os animais indefesos, mau aluno e mau colega, alternando as fugas e a delinquência, até chegar a uma vida adulta irresponsável, seguida de instabilidade profissional, e cuja única constância seria judiciária, penitenciária e asilar. Tende-se a substituir, então, a escuta clínica do sujeito pela pesquisa de anomalias comportamentais que a referência ao conformismo social transforma em sinais da patologia.

Rev. Latinoam. Psicopat. Fund., São Paulo, v. 12, n. 2, p. 285-302, junho 2009 


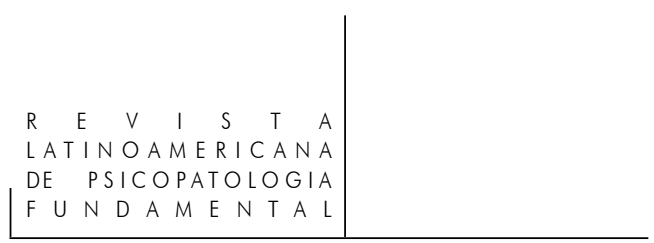

Chamamos a atenção aqui para o relevante fato de que o DSM-IV-TR, embora não seja o responsável pela tipologia negativa da psicopatia (que, como vimos, consolidou-se com Cleckley, sendo reproduzida também pela CID-10), acentua a correlação desta categoria nosológica com a delinquência, ao listar comportamentos delituosos típicos como sendo as principais características arquetípicas da personalidade antissocial, cujo emblema máximo é o primeiro critério do item A que exige a "execução repetida de atos [ilícitos] que constituem motivo de detenção". ${ }^{11}$ Com isso, as fronteiras entre o normal e o patológico, no que tange à psicopatia, tornaram-se mais fluidas, embora, paradoxalmente, os critérios diagnósticos propostos para essa categoria tenham se tornado mais rigorosos; isso se explica na medida em que o rigor desses critérios acompanhou em proporção sua banalização na direção dos comportamentos normais (não patológicos, apesar de desviantes para com a norma moral). ${ }^{12}$

Ao longo do desenvolvimento do conceito de psicopatia, predominou entre os autores a ideia de um desvio de caráter, avaliado segundo os moldes morais e os parâmetros éticos do relacionamento humano, o que desloca o problema da caracterização de patologia, no sentido médico, para o de anomalia ou diferença en-

11. Em sua crítica ao DSM, Kernberg assinala que o verbete psicopatia desse manual "inclui delinquentes com maquiagens de personalidades muito diferentes, obscurecendo a distinção entre determinantes socioculturais e econômicos da delinquência, de um lado, e psicopatologia da personalidade, de outro" (apud Shine, 2000, p. 19). A inclusão no DSM do diagnóstico de "transtorno de conduta" na infância ou adolescência como pré-requisito necessário para o diagnóstico de psicopatia na vida adulta, por um lado, representou um avanço já que permitiu conceber a psicopatia de uma perspectiva longitudinal; contudo, por outro lado, os critérios diagnósticos adotados para "transtorno de conduta" com base em comportamentos criminosos e delituosos (defraudação/furto, vandalismo, agressão física etc.) reforçam a correlação desta categoria nosológica com a delinquência infanto-juvenil.

12. O psicólogo norte-americano Robert Hare (1996), importante pesquisador da personalidade antissocial com longa experiência clínica com populações carcerárias, assinala que o DSM permite um diagnóstico com elevada confiabilidade e duvidosa validade. Criador de uma escala de avaliação da psicopatia chamada Hare psychopathy checklist-revised (Hare PCL-R) muito difundida em vários países, Hare não concorda com a identificação entre psicopatia e transtorno da personalidade antissocial promovida por esse manual. Com base no modelo nosológico dimensional, Hare sugere que a psicopatia seria a forma mais grave de manifestação do transtorno da personalidade antissocial; haveria, portanto, diversas nuanças de manifestações da síndrome, desconsideradas pelo DSM, que impõe uma lista de critérios sintomáticos rigorosos de inclusão ou exclusão ao tipo antissocial, baseados tão somente no comportamento observável do indivíduo, e não em aspectos de sua personalidade.

Rev. Latinoam. Psicopat. Fund., São Paulo, v. 12, n. 2, p. 285-302, junho 2009 
tre estilos de existência que podem ser indesejáveis ${ }^{13}$ (Morana; Mendes Filho, 2001, p. 106). A CID-10 confirma esse aspecto ao caracterizar os transtornos da personalidade como "a expressão característica da maneira de viver do indivíduo e de seu modo de estabelecer relações consigo próprio e com os outros" (OMS, 2000, p. 351).

A psicopatia certamente é uma das anomalias da personalidade que apresenta consequências sociais mais graves, dadas as condutas antissociais dos psicopatas, associadas ao delito e ao crime. Nesse sentido, pode-se questionar se a medicalização desta condição não refletiria um esforço do Estado republicano de reforçar o seu controle por outros meios, para além daquele já exercido pelo direito positivo? Um misto de psiquiatria e Poder Judiciário, tratamento e punição, certamente mostrar-se-ia mais eficaz em sua função de controle social desses desviantes. ${ }^{14}$

À guisa de conclusão, resta-nos questionar se a psicopatia, enquanto categoria psiquiátrica do DSM, não acabaria por se aplicar sobretudo aos delinquentes e criminosos $?^{15}$ Em caso afirmativo, o que justificaria esta expansão da psiquiatria norte-americana rumo ao normal, a não ser o controle dessas pessoas pelo viés da medicina, por meio de uma gestão dos fatores de risco populacionais? Em nossa época atual, na qual se discute com tanta paixão a pertinência da aplicação das chamadas penas alternativas aos casos de delitos e crimes menos graves e o respaldo das práticas psi na ressocialização dos apenados contemplados com essa medida, trata-se de uma questão intrigante.

13. De certo modo, essa concepção reflete as ideias de Schneider (1968) apresentadas no subitem "O surgimento e a evolução do conceito de psicopatia".

14. Esse é o argumento central de Lanteri-Laura (1994), para quem a burguesia, ao ascender ao poder após a Revolução Francesa, laicizou a repressão sexual, chamando a ciência médica à responsabilidade no trato com as perversões para fins de controle, antes, exercido de forma despótica pela Igreja. O direito positivo, embora seja liberal em matéria de sexualidade (exceto com relação às práticas sexuais não consentidas ou abusivas), condena com veemência os ataques à pessoa e à propriedade; daí os psicopatas, por sua característica de infligir frontalmente o Código Penal em seus valores canônicos (a propriedade e a vida), serem presas de toda uma rede de significações jurídicas, para além do aparato médico que sobre eles recai.

15. O manual que serve de referência aos psiquiatras da nova geração: Kaplan e cols. (1997) - uma espécie de DSM ilustrado, tende a confirmar nossa suspeita ao enfatizar que "Nas populações carcerárias, a prevalência da personalidade antissocial pode chegar a 75\%" (p. 692).

Rev. Latinoam. Psicopat. Fund., São Paulo, v. 12, n. 2, p. 285-302, junho 2009 


\section{Referências}

Associação Psiquiátrica Americana (APA). Manual Diagnóstico e Estatístico de Transtornos Mentais. 4. ed. - Revista (DSM-IV-TR). Porto Alegre: Artmed, [2000] 2002.

BERCHERIE, P. Os fundamentos da clínica: história e estrutura do saber psiquiátrico. Rio de Janeiro: Jorge Zahar, 1989.

CALDEIRA, M. V. V. Psicopatia: teoria e clínica. 1979. 337 p. Tese (doutorado em Psiquiatria), Universidade Federal do Rio de Janeiro.

Cleckley, H. M. The Mask of Sanity: An Attempt to Clarify Some Issues About the So-Called Psychopathic Personality. Fifth Edition. Augusta, Georgia: Emily S.

Cleckley, 1988. 485 p. [Scanned facsimile]

Ferraz, F. C. Perversão. São Paulo: Casa do Psicólogo, 2000.

FReUd, S. (1911). Notas psicanalíticas sobre um relato autobiográfico de um caso de paranoia (dementia paranoides). In: Edição Standard Brasileira das Obras Psicológicas Completas de Sigmund Freud. Rio de Janeiro: Imago, 1996. v. XII, p. 15-89.

HARE, R. D. Psychopathy and Antisocial Personality Disorder: a case of diagnostic confusion. Psychiatric Times, v. 13, n. 2, p. 39-40, 1996.

Kaplan, H. I. et al. Compêndio de Psiquiatria: ciências do comportamento e psiquiatria clínica. 7. ed. Porto Alegre: Artes Médicas, 1997.

LANTERI-LAURA, G. Leitura das perversões: história de sua apropriação médica. Rio de Janeiro: Jorge Zahar, 1994.

Leite, M. P. S. Psicanálise e neurociências. In: Magalhães, M. C. R. (Org.).

Psicofarmacologia e psicanálise. São Paulo: Escuta, 2001. p. 137-153.

Moraes, T. de (Org.). Ética e psiquiatria forense. Rio de Janeiro: Edições IPUB/Cuca, 2001. p. 103-133.

Morana, H.; Mendes Filho, R. B. Revisão sobre os transtornos de personalidade. In: Organização Mundial da Saúde (OMS). Classificação de Transtornos Mentais e de Comportamento da CID-10 - Descrições clínicas e diretrizes diagnósticas. Porto Alegre: Artmed, 1993.

. Classificação Estatística Internacional de Doenças e Problemas Relacionados à Saúde. 10. Revisão (CID-10). São Paulo: Edusp, [1992] 2000.

QueIroz, E. F. A clínica da perversão. São Paulo: Escuta, 2004.

Roudinesco, E. Por que a psicanálise? Rio de Janeiro: Jorge Zahar, 2000.

SCHNEIDER, K. Personalidades psicopáticas. In: Psicopatologia clínica. São Paulo: Mestre Jou, 1968. p. 41-74. 


\section{ARTIGOS}

Shine, S. K. Psicopatia. São Paulo: Casa do Psicólogo, 2000.

VALAs, Patrick. Freud e a perversão. Rio de Janeiro: Jorge Zahar, 1990.

\section{Resumos}

(De H. Cleckley al DSM-IV-TR: la evolución del concepto de psicopatía rumbo a la medicalización de la delincuencia)

La psicopatía es descrita como la personalidad antisocial por los manuales nosográficos contemporáneos: CIE-10 y DSM-IV-TR. Contrastando tales nosografías entre sí, con relación a los criterios de diagnósticos propuestos para la psicopatía, se observan las consecuencias de su operacionalización, particularmente las derivadas del DSM. Entre ellas, se destaca: (1) la degradación del diagnóstico a una mera lista protocolar; (2) la acentuación de la relación histórica entre la psicopatía y la delincuencia.

Palabras claves: Psicopatía, personalidad antisocial, CIE-10, DSM-IV-TR

(De H. Cleckley au DSM-IV-TR: l'évolution du concept de la psychopathie vers la medicinalisation de la délinquance)

La psychopathie est décrite comme personnalité antisociale par les manuels nosographiques contemporains, comme le CIM-10 et le DSM-IV-TR. La comparaison de ces nosographies entre elles par rapport à leurs critères de diagnostique de la psychopathie permet d'obtenir les conséquences opérationnelles, surtout en ce qui concerne le DSM, parmi lesquelles on retiendra spécialement: (1) la dégradation du diagnostique au simple classement protocolaire; (2) l'accentuation du rapport historique entre la psychopathie et la délinquance.

Mots clés: Psychopathie, personnalité antisociale, CIM-10, DSM-IV-TR

(From H. Cleckley to DSM-IV-TR: the evolution of the concept of psychopathy toward the medicalization of delinquency)

Psychopathy is described in two contemporary nosographic handbooks (ICD-10 and DSM-IV-TRO) as the condition of having an anti-social personality. This article contrasts these nosographies in terms of the diagnostic criteria used for psychopathy. The consequences of this use, especially that presented by the DSM, are discussed, such as (1) the degradation of diagnoses to the mere filling out of forms; (2) emphasis on the historical correlation between psychopathy and delinquency.

Key words: Psychopathy, anti-social personality, ICD-10, DSM-IV-TR. 


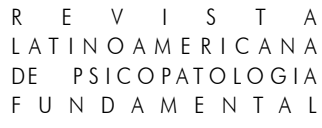

Citação/Citation: HenriQues, R.P. De H. Cleckley ao DSM-IV-TR: a evolução do conceito de psicopatia rumo à medicalização da delinquência. Revista Latinoamericana de Psicopatologia Fundamental, São Paulo, v. 12, n. 2, p. 275-302, jun. 2009.

Editor do artigo/Editor: Prof. Dr. Manoel Tosta Berlinck.

Recebido/Received: 17.4.2008 / 4.17.2008 Aceito/Accepted: 22.5.2008 / 5.22.2008

Copyright: (C) 2009 Associação Universitária de Pesquisa em Psicopatologia Fundamental/ University Association for Research in Fundamental Psychopathology. Este é um artigo de livre acesso, que permite uso irrestrito, distribuição e reprodução em qualquer meio, desde que o autor e a fonte sejam citados/This is an open-access article, which permits unrestricted use, distribution, and reproduction in any medium, provided the original author and source are credited.

Financiamento/Funding: Esta pesquisa foi financiada pela Fundação de Apoio à Pesquisa do Estado do Rio de Janeiro - Faperj /This research has been funded by the Ministry of Health, Brazil, and by the Fondation for Research Support of the State of Rio de Janeiro Faperj.

Conflito de interesses: $\mathrm{O}$ autor declara que não há conflito de interesses/The author declares that has no conflict of interest.

Psicólogo, psicanalista, mestre e doutor em Saúde Coletiva pelo Instituto de Medicina Social da Universidade do Estado do Rio de Janeiro - IMS/UERJ (Rio de Janeiro, RJ, Brasil); professor da Universidade Federal de Sergipe (Aracaju, SE, Brasil).

Av. Prof. Acrísio Cruz, 30/503- Salgado Filho 49020-210 Aracaju, SE

e-mail: rsphenriques@ hotmail.com 